\title{
A Religião e o Discurso de Mulheres sobre o Abortamento ${ }^{1}$
}

\author{
Daniela Vitti Ribeiro da Silva ${ }^{2}$ \\ Marilene Cabello Di Flora \\ Universidade do Sagrado Coração
}

\begin{abstract}
RESUMO - Esta pesquisa teve como objetivo verificar a proximidade entre o discurso religioso e o de fiéis a respeito da prática abortiva, analisando os discursos cristãos (católico e espírita) e não-cristãos (mórmon e Seicho-No-Ie). Por meio da análise de 40 entrevistas, confirmou-se a proximidade dos discursos e percebeu-se que a religião é um fator que pode exercer alguma influência sobre a decisão da mulher de realizar um abortamento, apesar de outros fatores (econômicos e sociais) terem aparecido com maior frequência. $\mathrm{O}$ discurso de algumas mulheres revelou a importância da religião como fonte de conscientização a respeito da importância da vida, caracterizando um fator de proteção do abortamento.
\end{abstract}

Palavras-chave: mulher; abortamento; religião.

\section{Religion and the Women Speech on Abortion}

\begin{abstract}
This research aimed at verifying the proximity between the religious and the faithful women speech on the abortive practice, analyzing the speeches of Christians (Catholic and Spiritualistic) and no-Christians (Mormon and SeichoNo-Ie) religions. Through the analysis of 40 interviews, it was confirmed the proximity of these speeches. It was also noticed that religion is one factor that can exert some influence in the decision of having an abortion, in spite of other factors, such as economical and social ones, have appeared more frequently. The speech of some women showed the importance of religion as a source of awareness with regard to the importance of life, characterizing a protection factor against abortion.
\end{abstract}

Keywords: woman; abortion; religion.

No Brasil, o aborto encontra-se no terceiro lugar entre as causas de mortalidade materna, segundo o Ministério da Saúde (2001). Deve, assim, ser considerado um problema de saúde pública, necessitando que estratégias preventivas sejam desenvolvidas.

Uma pesquisa afirma que $23,5 \%$ dos parceiros recusam o uso de contracepção, o que acarreta um maior número de gravidez indesejada, uma das causas principais do aborto provocado (Ministério da Saúde, 2008). Tal comportamento é um exemplo de como é vivenciada a sexualidade feminina em uma sociedade patriarcal. Segundo Maia (2008), a Igreja tem um importante papel na construção cultural da sexualidade feminina, ainda mais se for considerado que a educação de mulheres para serem mais passivas e submissas facilita muito a aceitação de crenças e o envolvimento religioso. De fato, algumas pesquisas mostram que as mulheres têm maior envolvimento religioso do que homens (Beit-Hallahmi \& Argyle; De Vaus \& McAllister; citados em Dalgalarrondo, 2008).

Não podemos nos esquecer, no entanto, que a religião também exerce um papel muito importante na sociedade, sendo visto por seus integrantes como um ambiente de apoio emocional para seus conflitos. Nesse sentido, a religião pode ser um espaço de acolhimento e alívio das angústias que a prática do aborto pode acarretar à mulher.

1 O presente artigo é resultado do Programa de Iniciação Científica da Universidade do Sagrado Coração, bolsa FAP.

2 Endereço para correspondência: Rua Francisco Peixoto Gomide, 125, Vila Honorina. Agudos, SP. CEP 17120-000. Telefone: (14) 3261-2075. Fax: (14) 3262-2658. E-mail: danivitti@gmail.com.
Diante da relevância da religião na vida das mulheres e da problemática do abortamento no Brasil, surgiu o interesse em verificar qual o papel da religião na prevenção do abortamento. O problema que norteou esta investigação pode ser assim descrito: qual a proximidade de diferentes discursos religiosos com os discursos das mulheres praticantes dessas religiões sobre o abortamento?

Foram delimitadas quatro religiões para o presente estudo, sendo duas religiões cristãs, católica e espírita, e duas religiões não cristãs, mórmon e Seicho-No-Ie. A escolha das religiões se deu pela amplitude de seguidores, sendo que o Brasil é o país com maior número de católicos e espíritas, e os mórmons tiveram um crescimento de $80 \%$ desde sua chegada ao país. Apesar de estar entre os novos grupos religiosos, a Seicho-No-Ie também apresenta um número expressivo de adeptos, 151.082 (Dalgalarrondo, 2008).

A classificação da religião espírita como cristã deu-se pela afirmativa de Dalgalarrondo (2008) de que o espiritismo, no Brasil, sofreu grande influência católica. A classificação da religião mórmon como não cristã, por sua vez, foi baseada na afirmativa de Gheller (2002) de que a doutrina dos mórmons distancia-se muito dos ensinamentos de Jesus Cristo.

Dentre as religiões cristãs selecionadas, ambas se posicionam contrárias ao abortamento. O Catolicismo se baseia, segundo Barberi (1995) e Rolim (2007), no fundamento que diz "não matarás". Enquanto que o espiritismo considera o aborto um crime por acreditar na existência do espírito antes mesmo da concepção, devido ao conceito da reencarnação (Kardec, 2007; Verardo, 1987). No entanto, ambas as religiões abrem exceção ao aborto indireto, realizado para salvar a vida da mulher. 
Em religiões consideradas não cristãs, as opiniões não diferem em muitos aspectos. A religião dos mórmons, segundo Walsh e Walsh (2001), considera que o espírito é enviado ao corpo em algum momento entre a concepção e o nascimento e que a vida de uma criança é sagrada, o que caracteriza uma posição contra ao abortamento. Já a SeichoNo-Ie valoriza a vida e é contra a prática do abortamento, pois acredita que mesmo se a criança morrer logo em seguida ao seu nascimento, tanto a mãe como a criança terão cumprido sua missão (Ribeiro, 2006).

Dessa forma, esse trabalho foi desenvolvido com o intuito de avaliar a proximidade do discurso de líderes religiosos e o discurso de mulheres frequentadoras de instituições religiosas, sobre o abortamento, visando verificar se a religião aparece como um possível fator de proteção frente ao aborto.

\section{Método}

\section{Participantes}

Para cada religião pesquisada, foram entrevistados três líderes religiosos e sete féis (mulheres acima de 18 anos). Como líderes entendeu-se indivíduos responsáveis por disseminar a doutrina de sua respectiva religião durante atividades como missas, cultos e encontros e que possuem alguma posição de liderança dentro da hierarquia da instituição religiosa. As fiéis entrevistadas foram escolhidas aleatoriamente após participarem de atividades religiosas.

\section{Procedimento}

Realizou-se um trabalho qualitativo. As informações foram coletadas por meio de entrevistas semi-estruturadas, as quais foram gravadas após os participantes assinarem o Termo de Consentimento Livre e Esclarecido. Apenas quatro religiões foram estudadas, duas cristãs (católica e espírita) e duas não cristãs (mórmom e Seicho-No-Ie). O trabalho foi aprovado pelo Comitê de Ética em Pesquisa da Universidade em que foi desenvolvido.

Dois questionários foram construídos, um direcionado aos líderes religiosos, com o objetivo de caracterizar seu discurso referente ao aborto. O questionário desenvolvido para as fiéis teve como intuito verificar a posição dessas sobre o abortamento e identificar a presença da religião em seu discurso, como sendo preventiva ou não quanto à realização de um abortamento.

\section{Resultados}

Os resultados foram agrupados a partir das temáticas que serão apresentadas e discutidas a seguir.

\section{Significado e posição pessoal}

Todos os participantes veem o abortamento como a interrupção de uma vida, possuindo uma posição contrária ao aborto. Entre os líderes, apenas os das religiões espírita e mórmon apresentam exceções para o abortamento, as quais se assemelham às previstas por lei, conforme exemplificado pela fala de um líder espírita: "Que nós podemos quando há risco da vida da mãe, pode-se praticar o aborto. Aborto necessário, né” (L. A. I., 65 anos).

Uma das sete mulheres espíritas afirma não ser capaz de julgar uma mulher que comete um aborto, sendo que ela mesma poderia realizar um abortamento em uma dada situação de desespero, mesmo possuindo suas crenças e valores. Apesar de estar consciente dos preceitos de sua religião, umas das sete fiéis católicas acha que o uso de anticoncepcionais deveria ser permitido pela Igreja, além de se posicionar contra o fato do abortamento ser proibido pela Igreja até mesmo quando há anencefalia fetal (Barberi, 1995). Essa fiel acredita que a mulher tem o direito de fazer suas escolhas: "Esse caso do que não tem cérebro né, da criança que sabe que vai morrer. Eu acho que teria liberdade dessa mãe ... tirar essa criança antes" (L. C. G. L., 47 anos).

Uma das fiéis mórmon afirma que a mulher tem livre arbítrio para decidir realizar o abortamento ou não. Duas das sete mulheres da Seicho-No-Ie posicionaram-se favoráveis ao abortamento, uma em casos de estupro, e outra como último recurso. Apesar das exceções concedidas, o discurso das mulheres se assemelha bastante ao discurso religioso, tanto pela posição contrária ao aborto, como pela justificativa de que a vida tem início na fecundação, sendo assim o aborto considerado um crime por quase todos os sujeitos: "A minha posição é contra, né. Porque é a interrupção da vida" (W. C. S. C., fiel mórmon, 46 anos).

Fatores desencadeantes da prática abortiva. Os principais fatores citados por líderes e fiéis das quatro religiões como desencadeadores do abortamento foram: aspecto financeiro, psíquico (medo, imaturidade), social (família, companheiro), estupro, falta de conhecimento, gravidez indesejada e deformidade fetal. Apesar de não ter sido mencionado com tanta frequência, a falta de religião e a desvalorização da vida também estiveram presentes nos discursos como sendo um dos fatores que influencia a mulher na questão do abortamento, como vemos a seguir na fala de uma fiel espírita e de uma fiel da Seicho-No-Ie: “... não é porque você tá na igreja que você não vai praticar o aborto né. Mas, que isso, às vezes, ajuda $\mathrm{a} . .$. te conscientizar, te ponderar um pouco mais, com certeza" (R. C. S. P. M., fiel espírita, 31 anos); “... Se ela vê pelo lado espiritual, pelo lado de Deus, pelo lado da luz, nenhuma mulher faz aborto, nenhuma" (I. F. O., fiel da Seicho-No-Ie, 54 anos).

Posição, atitudes e ações da religião em relação à prática abortiva. Este item teve como objetivo verificar o conhecimento das fiéis sobre os preceitos da religião em relação ao abortamento. As mulheres apresentaram conhecimentos suficientes sobre as considerações da sua religião frente o 
abortamento, não havendo diferenças relevantes entre os discursos, uma vez que apenas uma fiel católica, das $28 \mathrm{mu}-$ lheres entrevistadas, apresentou dúvida referente à posição da sua religião em casos de estupro.

\section{Discussão}

Diante do objetivo proposto pelo trabalho, o qual era identificar o nível de concordância entre o discurso religioso e o discurso de mulheres praticantes de religiões cristãs e não-cristãs a respeito da prática abortiva, verificou-se que o discurso das fiéis é bastante próximo ao discurso dos líderes de suas religiões. As divergências encontradas entre o discurso religioso e o de mulheres não foram significativas. Segundo Dalgalarrondo (2008), a religião tem papel importante na construção da identidade do sujeito e de seus pontos de vistas, o que está de acordo com os achados deste estudo, os quais evidenciam o discurso religioso sobreposto ao discurso das mulheres estudadas.

Não foram encontradas diferenças significativas entre o discurso cristão e não-cristão, sendo que ambos são contrários ao abortamento, abrindo algumas exceções, que em geral são as permitidas por lei no Brasil.

A religião não foi citada com frequência como um fator protetor para o abortamento, prevalecendo os aspectos econômicos e sociais. Esse resultado confirma a hipótese levantada neste trabalho de que existem outros fatores de maior influência na decisão da mulher em realizar um abortamento. Por outro lado, constatou-se na fala de algumas mulheres, cristãs e não-cristãs, a indicação de que a religião também se constitui num fator de proteção ao abortamento, mostrando sua parcela de contribuição na prevenção do aborto, frente ao esclarecimento que a religião traz a respeito da vida e sua importância.

\section{Referências}

Barberi, P. (1995). Aborto: ponto de vista cristão. Petrópolis: Vozes.

Dalgalarrondo, P. (2008). Religião, psicopatologia e saúde mental. Porto Alegre: Artmed.

Gheller, E. G. (2002). Cultura religiosa: o sentimento religioso e sua expressão (6 $6^{\mathrm{a}}$ ed.). Porto Alegre: Mundo Jovem.

Kardec, A. (2007). O livro dos espíritos ( $3^{\mathrm{a}}$ ed.) (E. N. Bezerra, Trad.). Rio de Janeiro: Federação Espírita Brasileira. (Trabalho original publicado em 1857)

Maia, B. M. (2008). Direito de decidir: múltiplos olhares sobre $o$ aborto. Belo Horizonte: Autêntica.

Ministério da Saúde (2001). Parto, aborto e puerpério: assistência humanizada à mulher. Brasília: Área Técnica de Saúde da Mulher, Ministério da Saúde.

Ribeiro, A. A. (2006). Uma jornada em defesa da vida. SeichoNo-Ie: Mundo Ideal, 139, 27-30.

Rolim, R. C. (2007). Justiça criminal e condição feminina na capital da república em meados do século XX. Sociedade e Estado (Brasília), 22, 97-133.

Verardo, M. T. (1987). Aborto. Um direito ou um crime? (2 ed.). São Paulo: Moderna.

Walsh, W. J., \& Walsh, J. S. (2001). Abortion. Retirado em 23/05/2004, de http://www.lightplanet.com/mormons/daily/ sexuality/Abortion EOM.htm. 